\title{
IMPROVING DESIGN AND DELIVERY OF FAMILY PLANNING SERVICES TO MEET THE UNMET NEED FOR CONTRACEPTION IN QUETTA BALOCHISTAN
}

\author{
Naiha Sagheer ${ }^{1}$, Saleemullah ${ }^{2}$, Noureen Latif ${ }^{3}$, Tabinda Zaman $^{3}$ \\ ${ }^{1} \mathrm{KRL}$ Hospital Islamabad \\ ${ }^{2}$ Department of Community Medicine Quetta Institute of Medical Sciences Quetta. Balochistan \\ ${ }^{3}$ Sarhad University Islamabad Campus. \\ Correspondence:Saleemullah.Email: doc_saleem@hotmail.com
}

\begin{abstract}
Background: Approximeately 24 percent of married women of reproductive age in Pakistan would like to adopt family planning, but are unable to avail the means to practice contraception. This study has been conducted to find out frequency and perception about family planning practices and further to explore and analyze the causes of failure to meet the demand for contraception.

Methods: A cross-sectional study was conducted on married females of reproductive age group and married males while visiting the outpatient departments of two hospitals of Quetta from January to September 2017. They were interviewed by researchers through a structured, reliable and pretested questionnaire. The data obtained and analyzed by using SPSS 21 version.

Results: $76 \%$ of participants were in favour of practicing yet only $33.8 \%$ had actually practiced it sometime during their reproductive years. The major reasons for not using family planning were the apprehension of harmful effects of contraceptive methods (52.6\%), non-supportive partner $(30 \%)$, unavailability of services $(11.4 \%)$ and religious constraints $(6 \%)$. The mass media was the main source of motivational information( $69 \%)$ followed by Lady health workers.

Conclusion: The current prevalence of family planning is still not at the expected level, There is a dire need of the continued use of mass media and services of community health workers to raise awareness. The practice of modern contraceptive methods can be enhanced by provision of client-centered quality services.. An increase in the number of family planning centers along with an efficient functioning, monitoring, and evaluation are also required to address unmet needs of the community near their doorstep.
\end{abstract}

Keywords: Family planning services, unmet needs, awareness, mass media

\section{Introduction}

The high rate of population growth of Pakistan and its adverse impact on the successful implementation of development strategies has long been recognized (1). The preliminary results of the population and housing census 2017 alerted us to the serious socio-economic, demographic and public health implications of a population estimating almost 208 million with an average growth rate of $2.4 \%$ (2). The population issue is at the center of the agenda for Sustainable Development Goals (SDGs). Therefore the impact of family planning has been well recognized as the key to achieving the Sustainable Development Goals (SDG) targets across social, economic and environmental areas by the year 2030 (3). In Pakistan, the family planning programs have been in place since the late 1950s, but until now the country's family planning approach has failed to create a discernible dent in the population growth. The contraceptive prevalence rate has remained almost unchanged over the last 10 years (4). About $24 \%$ of married women of reproductive age in Pakistan would like to adopt family planning but are unable to avail the means to do so. One in four in Pakistan has an unmet need for contraception, which is the highest such rate in the region. Unmet need for family planning defined as the proportion of women wishing to limit or postpone childbirth, but not using contraception, has been central to reproductive health efforts for decades and still remains relevant for most policymakers and family planning programs in low and middle-income countries. There is still a lag in contraceptive uptake across regions, resulting in high unmet need due to various socioeconomic and cultural factors. Two-thirds of women using family planning in Pakistan do so to space 
births, whereas, the majority of women with an unmet need has a need for limiting families $(5,6)$. Balochistan presently has the worst maternal and infant mortality rate in the country. Similarly, for the past six years, the unmet need for family planning services has remained constant at $31 \%$ in Balochistan, whereas the rest of the county has seen a $5 \%$ drop from $25 \%$ to $20 \%$. Use of modern contraceptive methods in the province stands at $16 \%$, whereas the national average is $26 \%$. Unmet need is the highest in Balochistan as a proportion of the population and the lowest in Punjab. These numbers translate to 3.5 million, requiring limiting services and 2.5 million requiring spacing services. There is only slightly more unmet need in urban than rural locations $(7,8)$. A number of factors are responsible for the unmet need for family planning in Pakistan making it a significant public health issue (4). The prevalence of unmet need for family planning is a primary justification of family planning programs, but the causes of unmet need have not been much explored (9). Therefore this study was carried out to assess the local perception, level of adoption of contraceptive practices and further explore and analyze the reasons of failure and modify the services design as well as delivery to make them more effective in reducing unmet need.

\section{Methodology}

A descriptive cross-sectional study was conducted in two tertiary care public hospitals of Quetta from January to September 2017. A total sample size of $n=532$ married males and females in the reproductive age group (15-49 years old) were selected through non-probability purposive sampling technique. Sample size was calculated using Open-Epi software by taking data of total population of married couples by population census 1998 and 2017 (10-12). Unmarried and nulliparous females and unmarried males were excluded from the study. Outpatient departments of the hospitals were approached to interview the relevant subjects. Data was collected through a self structured questionnaire after obtaining approval from ethical committees of the hospitals and verbal informed consent of the respondents. The information was obtained from the participants about their, knowledge, intentions to practice contraception, perceived social, family and spousal support, quality and availability of the family planning services and reasons for not using the contraceptive methods. Data were analyzed through SPSS version 21 version.

\section{Results}

A total number of 532 married males and females were included in this study. All the respondents were interviewed. The socio-demographic characteristics of the study population showed that $22.5 \%$ of women belong to age group $18-27$ years, $47.5 \%$ were $28-35$ years and $30 \%$ were above 35 years of age. About $14 \%$ of women were employed, $85 \%$ were housewives. Regarding husband occupation $45 \%$ were labourer $27.5 \%$ were in the government job, $17.5 \%$ were the businessman and $10 \%$ were unemployed. About $42.5 \%$ husbands were illiterate, $22.5 \%$ had primary education, $16.5 \%$ had secondary, $12 \%$ intermediate, $2 \%$ graduate and $4.5 \%$ had post-graduate education. About $75 \%$ of women were illiterate, $9 \%$ had primary education, and $6.5 \%$ secondary, $7.5 \%$ intermediate and $2 \%$ had graduation. About $69.5 \%$ of the respondents were married before 18 years of age while $26.5 \%$ were married at the age of $19-29$ years and $4 \%$ were married above 30 years of age. About $54 \%$ live in the nuclear family, $38 \%$ joint family and $8 \%$ in the extended joint family system. Regarding the desired number of children, women responded one child (3\%), 2-3 children $(11 \%), 4-5 \quad(37.5 \%)$, more than five children (36\%), $5.5 \%$ said that children are God gifted and $7 \%$ did not answer. $67 \%$ had knowledge about at least one modern contraceptive method. Out of 532 respondents $(41 \%)$ had 3 or less issues and $(59 \%)$ had 4 or more issues. The biggest reason for having more than 3 was non-use of contraception. This study revealed that although $76 \%$ were in the favor of practicing family planning services yet only $33.8 \%$ of the study population had actually practiced it sometimes during their reproductive years.

Table 1: Perception regarding family planning services $(n=532)$

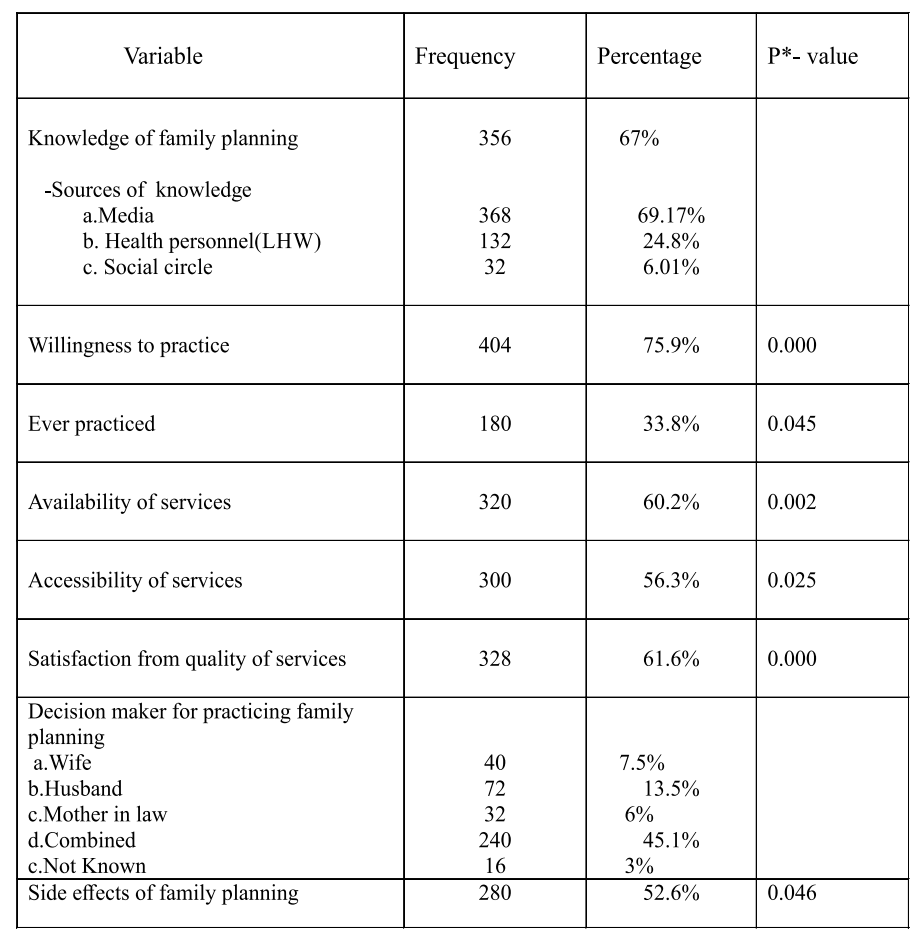

${ }^{*} P$-value was computed between knowledge of the respondents with other variables

$45 \%$ users were practicing family planning with the cooperation of their partner. In $13.5 \%$ of users decision was taken only by husband, and in $7.5 \%$ by the wife. Mass media was the main source of motivational information(69\%)followed by lady health workers. About half of users believed that family planning is necessary 
for the health of the mother. other believed brought up of children is the main reason.while in some social and economic stabilization is the main reason. $33 \%$ respondents have practiced the different contraceptive methods as shown in table - II

Table 2: Trends in the practice of family planning methods $(n=180)$

\begin{tabular}{|l|c|c|c|}
\hline Method & Frequency & Percentage & P Value \\
\hline Condoms & 56 & $31.11 \%$ & 0.023 \\
\hline Oral contraceptive pills & 44 & $24.44 \%$ & 0.003 \\
\hline Injectable & 24 & $13.33 \%$ & 0.056 \\
\hline $\begin{array}{l}\text { Intrauterine contraceptive } \\
\text { devices }\end{array}$ & 20 & $11.11 \%$ & 0.051 \\
\hline Sterilization & 36 & $20 \%$ & 0.028 \\
\hline
\end{tabular}

The major reason of not using family planning services were fear of side effects $(52.6 \%)$, unsupportive partner $(30 \%)$, unavailability of services $11.4 \%$ and religious contraints $6 \%$.

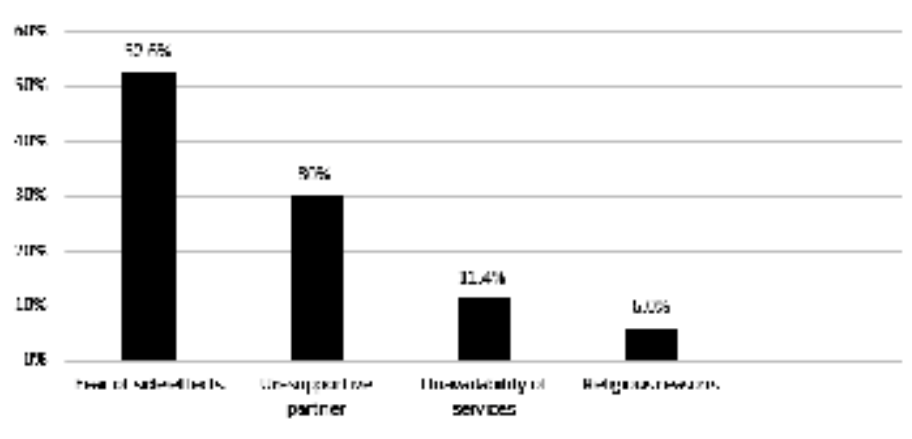

Figure 1: Reasons for not using contraception

\section{Discussion}

Women with unmet need for family planning are those who are in reproductive age and sexually active but are not using any method of contraception, and report not wanting any more children or wanting to delay the next child. The concept of unmet need points to the gap between women's reproductive intentions and their contraceptive behavior (13). The contraceptive prevalence rate is the proportion of women of reproductive age who are using (or whose partner is using) a contraceptive method at a given point in time (14). In this study, almost all of the participants had entered into marriage very early with women entering into marriage relatively earlier than men, which is similar to national figures that report that on average women enter into marriage at the age of 18 . Both men and women reported that the ideal number of children they would like to have in a family is four comprising boys and girls with the greater emphasis on boys. In line with findings of the PDHS 2012-13, males were reported as wanting more children than females (15).

This study showed that the knowledge for contraception was $67 \%$ as compared $84 \%$ and $99 \%$ in studies conducted in urban area of Sukkur Sindh and Lahore $(16,17)$ Despite high level of knowledge of contraception, the contraception prevalence rate remains too low. This study revealed that only $33 \%$ of study participants are practicing the family planning, whereas contraception performance final report 201516 showed that at national level $35.5 \%$ are using any method of contraception and only $26 \%$ using a modern method. At the provincial level, the contraceptive prevalence rates are $13.8 \%$ in Balochistan, $38.9 \%$ in Punjab, 25\% in Sindh and $46 \%$ in Khyber pakhtunkhaw. It was evident from the above situation that knowledge of family planning is not merely awareness of a method. Knowledge goes beyond than this, it encompasses understanding on the part of the user that how the method is used, its effectiveness in terms of preventing pregnancy, from where it can be obtained and what could be its side effects(18). According to world population council report in 2014, the Contraceptive Prevalence Rate(CPR) in Balochistan is increased from $14 \%$ in 2007 to $20 \%$ in 2013. Pakistan Bureau of Statistics(PBS) declared that CPR in Pakistan stands at $25.54 \%$, and $6.93 \%$ in Balochistan. Population Welfare department of Balochistan has shown in their report in 2014 the CPR in Balochistan stands at 19.5\%. Multiple indicator cluster survey in 2010 revealed the CPR of $14.7 \%$ in Balochistan. Due to different figures for CPR, there is a dearth of credible data, therefore actual situation regarding population control in the province cannot be ascertained $(19,20)$. About $75.9 \%$ respondents who were not current users of contraceptives reported that they intended to use contraceptives in future, nearly $40 \%$ of women in the extended post-partum period intend to use the method within the next year. At the global level, the regional averages differ very little ranging from $35 \%$ in the middle east to $41 \%$ in sub-Saharan Africa. For Asia, in Uzbekistan, only $20 \%$ and Bangladesh $58 \%$ postpartum women intend to practice a method in next year. Th recommended specific points of contact are pre-natal visits, during delivery stay, at the sixth-week postpartum follow up visit and at other appropriate points of contact (21).

In this Study, 45\% respondents revealed that decision of practicing contraception was combined by wife, and husband with the in-law's support. Study conducted in turkey showed that the percentage of married couple in their reproductive age using family planning in developed world reach as high as $68 \%$, whereas in developing countries ranges from $4 \%$ to $43 \%$, Similar finding in Madagascar showed that involving men increased their contraceptive use, encouraged women's use of contraception, and improved continuation rates. Many women discontinue contraceptives to please their husbands (22). A review of literature from seven African countries indicated that Spouse communication is positively associated with contraceptive use and the percentage of women using modern contraceptives is consistently higher in the group that had discussed with their husbands (23). 
The significance of support from the husband is undeniable, studies have shown that involving men in family planning counseling does increase contraception uptake, the satisfaction of clients, effective use of contraception and continuation. Urban women in Pakistan are more likely to adopt family planning when supported the option by their mother in law $(24,25)$.

According to this study, the family planning services were accessible to $56 \%$ of the respondents, the majority of them were satisfied with the quality of available services. These findings are different from the situation in rural areas of Balochistan as there are hurdles in accessing the family planning services. The key issues are the distance from services, transport problems, travel cost, timings of facility and availability of female staff, There are 544 Basic health units(BHU) run by the public sector in Balochistan do not have female staff. Almost one-fourth of monitored Basic health units (BHU) do not have the personnel to offer family planning counseling (26).

The notion that Islam keeps away families from using family planning has been ruled out as evident from this study. Only $6 \%$ of study participants give religion as the reason of non-use. In demographic health survey 201213 of Pakistan, the inhibiting influence of religious scholars and ulema is no longer the most significant factor in family planning decision-making and practice. However, in Khyber Pakhtunkhwa, the religious clerics discourage the use of family planning by spreading the misperception that contraception is incompatible with Islamic belief by delivering emotional appeals affect people and are followed by disapproval of those who practice family planning (27). The experiences of other Islamic countries are often seen as useful in informing and inspiring, especially in an area as sensitive and culturally linked to family planning. In Iran, the multisectoral approach was applied successfully. Stakeholders including community representatives, ministry officials, and religious leaders met with policymakers and collectively agreed that the country could not adequately feed, house, educate or provide jobs to its citizens at existing levels of population growth. This is the most unique and highly effective approach adopted in Iran (28). In Egypt religious leaders have played a major role in speaking out on the acceptability of birth control in the eyes of Islam. (29). In Indonesia, $99 \%$ of currently married women are knowledgeable about one modern contraceptive method, There is hardly any religious opposition to Family Planning in Indonesia (30). Exchange visits, conferences, and other forms of learning from other nations' experience, especially by sharing cultural and religious links between nations throughout the Muslim world were marked as important turning points and proved successful in Bangladesh, Jordon, and Morocco (31).

This study also identified the utilizing trends of different family planning methods in practicing participants. Condoms $(31.11 \%)$, oral contraceptive pills $(24.44 \%)$ and sterilization (20\%) were commonly used methods. Similar trends were also reflected in the contraception performance report 2014-15 by Pakistan Bureau of statistics regarding Balochistan an increase of $3.4 \%$ (condoms), $4.5 \%$ (oral contraceptive pills) $7.5 \%$ (contraceptive injectables) and $12.8 \%$ (Contraceptive Surgery) and a decrease of $8.1 \%$ has been noticed in use of Intrauterine contraceptive device (IUCDs) during the year 2014-15 compared with the last year 2013-14. A new modern contraception method in the form of a subdermal hormonal implant (Norplant) has been reported as a commonly practiced method in Punjab, Sindh, and KPK but not yet practiced in Baluchistan (32). The quality of care in family planning programs can be gauged from several factors including choice of contraceptive methods, information given to patients, technical competence, and interpersonal relationships (33).

In this study, $52.6 \%$ of participants showed their fear of side effects a major reason for not using any modern contraceptive method. According to Pakistan Demographic Health Survey 2012-13, among current users, two-thirds were not informed about side effects or issues with their method of choice, and around 72 percent were not told what to do in case of side effects or which other methods they could switch to do. Most Pakistani women using a modern contraceptive method did not receive adequate information or counseling on the various contraceptive methods they could choose from, their side effects or what to do when experiencing side effects..High rates of discontinuation are not surprising when women are given inadequate information to manage side effects and are not assisted in making informed choices about which method to use.(34). This study has limitations that sample size was less though the effort has been taken to select the participants to make the sample more representing the target population. Moreover, some level of misreporting cannot be ruled out due to low literacy level of interviewed respondents.

\section{Conclusion}

This study had revealed that majority of couples have the intention to adopt family planning practice. There is a good sign that household-level obstacles to family planning adoption are on the decline despite the conservative cultural environment, male dominance, lowest female literacy and empowerment in Balochistan in comparison to other provinces of Pakistan. At present, the prevalence of contraception is lowest in Balochistan in comparison to other provinces. The key issues are lack of awareness, apprehensions regarding harmful effects of contraceptive methods, accessibility, stock availability, and an uncooperative male partner but more particularly due to the lack of client-oriented quality consultations by properly trained female service providers who can deal with the major problem of apprehensions of possible side effects of contraceptive methods. In such scenario, the government must play a 
proactive role to invest in redesigning the system to make it responsive to address the major obstacles in adoption and more seriously emerging problem of high discontinuation rate of family planning practices. Use of mass media and services of community health workers can be arranged to help raise awareness more effectively in less literate population. Moreover, the current situation necessitates conducting in-depth health system research to identify the unexplored gaps behind the high level of unmet need of contraception..

\section{Refrences}

1. Mahmood N., Ringheim K. Factors Affecting Contraceptive Use in Pakistan. The Pakistan Development Review.1996;35(1):1 22.(PubMed)

2. Mohtashami H. Census 2017 Results. Public Health Implications. Paper presented at 8th Annual Public Health Conference, at Health Services Academy. 2017 Dec 6-7, Islamabad. Pakistan.

3. Albrectsen AB. Sustainable Development and Population Dynamics - Placing People at Centre. Speech delivered at the Open working group at sustainable development goals. UNFPA Headquarters NY 10158 USA. Available at: www.unfpa.org/press/sustainabledevelopment-and-population-dynamicsplacing-people-centre.

4. Punjani N "Determinants Associated with Unmet Need for Family Planning in Pakistan". Journal of Pioneering Medical Sciences Blogs. Sep. 2017. Available at:http://blogs.jpmsonline.com/ 2017/09/22/determinants-associated-withunmet-need-for-family-planning-in-pakistan/

5. Family Planning Services in Pakistan, Research and Development Solutions. Policy briefs. Series No. 2, Jan 2012. Available at. http://www.resdev.org/files/policy_brief/2/2.pdf

6. Wulifan JK, Berner S" A Scoping review on determinants of unmet need for family planning among women of reproductive age in LMICs." BMC women Health. 2016, 16:2 Available at: https://www.ncbi.nlm.nih.gov/pmc/articles/PMC 4714507I

7. Wasif S "Outrageous solution: For Balochistan, birth is more important than mother's life" The Express Tribune Pakistan. 2015 January 31. Available at:https://tribune.com.pk/story/ 830419/outrageous-solution-for-balochistanbirth-is-more-important-than-mothers-life/

8. Family Planning Services in Pakistan, Research and Development Solutions. Policy briefs. Series No. 6 March 2012. Available at. http://www.resdev.org/files/policy_brief/6/6.pdf

9. John B. Casterline, Aurora E. Perez. "Underlying Unmet Need for Family Planning in the Philippines" Studies in Family Planning, Vol. 28, No. 3 (Sep., 1997), pp. 173-191. Available at: http://www.jstor.org/stable/2137886

10. Census-Balochistan1998 .Area Population. Tables.1,2,3,4,5,6,7,12,19,20,29,30,32,33.Avail able at: http://www.pbscensus.gov.pk/sites/ default/files/DCR/balochistan/quetta.pdf

11. Provisional Census Results-2017 Balochistan : 15 .Available at: http://www.pbs.gov.pk/sites/ default/ files/ PAKISTAN\%20TEHSIL\%20 WISE \% $20 \mathrm{FOR} \% 20 \mathrm{WEB} \% 20$ CENSUS_2017.pdf

12. Population of Quetta- Census 2017. Available at: http://www.pakinformation.com/population/ quetta.html

13. Unmet Need for Family Planning'. Sexual and reproductive health. World Health Organization(2015) Available at: http://www. who.int/reproductivehealth/topics/family_planni ng/unmet_need_fp/en/

14. Reproductive Health Indicators: Guidelines for their generation, interpretation and analysis for global monitoring. (in press). Geneva, World Health Organization, 2006. Available at: http://www.who.int/whosis/whostat2006Contrac eptivePrevalenceRate.pdf

15. National Institute of Population Studies (NIPS) Pakistan Demographic and Health Survey 2012-

16. Shah NA, Nisar N, Qadri MH. Awareness and pattern of utilizing family planning services among women attending Urban Health Care Center Azizabad Sukkur. Pak J Med Sci 2008;24(4): 550-5.

17. Gohar A, Nizami NA, lodhi et all"The Knowledge and Practice of Various Contraceptive Methods for Family Planning among Married Males in Down Town Area of Lahore, Pakistan" PJMHS Vol 11 No 1 Jan - March 2017,30-34

18. Bajwa A. "Contraceptive Performance Report" 2015-16. Pakistan Bureau of statistics. Islamabad April 2017, 12-21

19. Family Planning Knowledge among currently Married women of District DG KhanPakistan.Pakistan centre of communication program. Final Report UNFPA 2015. http://ccppakistan.org.pk/wp-content/uploads/2015/01/ UNFPA.pdf

20. National Institute of Population Studies(NIPS) (Pakistan) and ICF International 2013." Pakistan Demographic and health survey 2012-13" Islamabad, Pakistan and Claverton Maryland, USA: NIPS and ICF International, Dec. 2013, 90-96

21. Ross J, Winfrey W. "contraceptive use, Intention to use and unmet need during an extended postpartum period. International family planning prospect 2001, 27:20-27

22. Population report. The Johns Hopkins School of Public health U.S.A.2005

23. Lala, T. Male involvement in family planning. A 
review of the literature and selected program initiation in Africa. The Pan African medical journal:2015:19;349

24. Wang CC, Vittinghoff E, Hua LS Yun WH, Rong ZM. "Reducing pregnancy and induced abortion rates in China: family planning with husband participation".Am J Public Health. 1998 Apr;88(4):646-8.

25. Kadir MM,Fikree FF, Khan A,Sajan F. Do mothers in law matter? Family dynamics and fertility decision making in urban squatter settlement of Karachi Pakistan. J Biosoc Sci. 2003 Oct;35(4):545-58 (Pub Med)

26. Few women health workers in Balochistan" 2010 http://www.irinnews.org/news/ 2010/07/07/few-women-health-workersbalochistan

27. Policy brief" Low use \& high discontinuation of modern contraceptives in Pakistan. Reasons and policy recommendations. Pakistan Demographic and health survey 2012-13. Available at: https://www.popcouncil.org/ uploads/pdfs/2015RH_PolicyBrief_RAF.pdf

28. Rahnama P, Hidarnia A, Shokravi FA, Kazemnejad A, Ghazanfari Z, Montazeri A. Withdrawal usersl' experiences of and attitudes to contraceptive methods: A study from the eastern district of Tehran, Iran. BMC Public Health 2010;10(779).

29. Private practitioner family planning project. Family planning dialogue. Rumors of contraception: Myths vs. facts. New Egypt J Med 1990 1990;4(2):1-21.

30. Schoemaker J. Contraceptive use among the poor in Indonesia. 2005; 31(3): 106-114. International Family Planning Perspectives 2005;31(3):106-14.

31. Marshal K. religious engagement family planning policies experience in six Muslim countries. Word faith development. (2015). Available at: https://s3.amazonaws.com/ berkley-center/151001Marshall Religious EngagementfamilyPlanningPoliciesExperience SixMuslimMajority Countries.pdf

32. Contraceptive Performance Report 2014-15. The government of Pakistan statistics division.pakistan Bureau of Statistics available at: http://www.pbs.gov.pk/sites/default/files/ contraceptive_performance_report_201415.pdf

33. Jain KA. "Improving the quality of care in family Planning" New York: Population Council.(2013). Available at: http://www.popcouncil.org/news/ improving-quality-of-care-in-family-planning

34. Zaidi B. Hussain S." Reasons for modern contraception use. Insight from Pakistan and neighboring countries". Literature review. New York. Population council (2015). Available at: https://www.popcouncil.org/uploads/pdfs/2015 RH_LitReview-RAF.pdf 